\title{
Characterization of temperature-induced changes in amorphous hydrogenated carbon thin films
}

\author{
Christian Hopf $^{a *}$, Thierry Angot ${ }^{b},{\text { Etienne } \text { Aréou }^{b} \text {, Thomas Dürbeck }}^{a}$, Wolfgang Jacob ${ }^{a}$, \\ Céline Martin ${ }^{b}$, Cédric Pardanaud ${ }^{b}$, Pascale Roubin $^{b}$, Thomas Schwarz-Selinger ${ }^{a}$ \\ ${ }^{a}$ Max-Planck-Institut für Plasmaphysik, EURATOM Association, Boltzmannstr. 2, 85748 Garching, Germany \\ ${ }^{b}$ Aix-Marseille Université, CNRS, PIIM UMR 7345, 13397 Marseille cedex 20, France
}

\begin{abstract}
Hard hydrogenated amorphous carbon thin films were heated in vacuum to different temperatures and held at these for at least $30 \mathrm{~min}$. Afterwards, the cooled-down samples were analyzed by various techniques. Strict and reproducible correlations were found between all the determined parameters and the annealing temperature. Single-wavelength ellipsometry shows that the real part of the refractive index of the films at $633 \mathrm{~nm}$ wavelength decreases with temperature while the extinction coefficient increases. It also shows swelling of the films with a thickness increase of about $50 \%$ for films heated to $\approx 1000 \mathrm{~K}$. The associated decrease of mass density is proportional to the decrease in refractive index. Ion beam analysis shows that hydrogen is released from the films during heating with only about $5 \%$ of the initial $\mathrm{H}$ remaining after annealing at $1300 \mathrm{~K}$ while no significant loss of carbon can be detected. The losses of hydrogen during heating are monitored by temperature programmed desorption and they are in good agreement with the ion-beam-analysis results. Raman spectroscopy delivers evidence of aromatization of the films under heat treatment. Indication of first structural changes is found already at $600 \mathrm{~K}$ while the quickest changes of the refractive index, thickness, and hydrogen content with temperature occur around $850 \mathrm{~K}$
\end{abstract}

Keywords: amorphous hydrogenated carbon, annealing, thermal stability, ellipsometry, optical properties, temperature programmed desorption, ion beam analysis

Published in Diamond \& Related Materials: Received 8 January 2013

Accepted for publication 11 May 2013

Available online 23 May 2013

Diamond \& Related Materials 37 (2013) 97-103

\section{INTRODUCTION}

Carbon-based thin films are used for a wide range of applications such as wear-resistant and anti-corrosive protective coatings [1,2]. Hydrogenated amorphous carbon thin films (hard a-C:H) are a subclass of such coatings [3]. The properties of a-C:H depend critically on the hydrogen content. Films with a high hydrogen content of typically up to $\mathrm{H} /(\mathrm{H}+\mathrm{C}) \sim 0.5$ are soft and polymer-like while a-C:H with a low hydrogen content of around $\mathrm{H} /(\mathrm{H}+\mathrm{C}) \sim 0.3$ are hard, wear resistant, and have a low coefficient of friction [4]. The applications of hard a-C:H are, however, restricted by its limited thermal stability. Above about $700 \mathrm{~K}$ the films lose hydrogen, become more graphitic, hardness decreases and wear increases $[5,6]$.

On the other hand, heat treatment of a-C:H (and other amorphous carbon) films after deposition has also beneficial effects. For instance, annealing was found to reduce compressive stress in the films $[5,7,8]$ limiting the maximum thickness above which the films delaminate from the substrate. Rapid thermal annealing of a-C:H coatings on silica optical fibers was shown to improve their protective qualities in harsh environments [9]. And heating by short laser pulses is a possibility for locally changing the electronic properties of a-C:H [10] and a-C [11] films.

In magnetic confinement nuclear fusion carbon was for a

*Corresponding author email: christian.hopf@ipp.mpg.de, telephone: +4989-32 99-26 17, fax: +49-89-32 99-96-26 17 long time the preferred choice for the first-wall material due to its favorable radiative properties [12]. A disadvantage that leads to its replacement in the designs of new fusion devices is, however, the high erosion yield that would seriously limit the lifetime of plasma-facing components. Furthermore, the eroded carbon is redeposited along with hydrogen from the plasma in locations with no or little erosion, producing layers that can have a high hydrogen content like soft a-C:H $[13,14]$ or can structurally resemble hard a-C:H $[15,16]$ and can contain substantial amounts of other elements [17]. In an all-carbon machine operating with a $\mathrm{D} / \mathrm{T}$ mixture this redeposition can be a dominant mechanism of the retention of radioactive tritium [18]. However, the amount of hydrogen isotopes stored in these layers strongly depends on the temperature they experience during plasma operation. At higher temperatures the layers are modified and lose hydrogen, leading to a decreased hydrogen isotope retention $[13,19]$.

Several studies in the literature have investigated the thermal stability and the temperature-induced modifications of various types of a-C:H films. With temperature programmed desorption (TPD) (also referred to as thermal desorption spectroscopy (TDS) or thermal effusion spectroscopy (TES)) it was found that the temperature at which thermal decomposition starts as well as the released species strongly depend on the initial composition of the film [20-24]. The onset of decomposition of hard a-C:H with $\mathrm{H} /(\mathrm{H}+\mathrm{C}) \sim 0.3$ is at about $700 \mathrm{~K}$ while for soft a-C:H with a hydrogen content around 0.5 it starts already at $100 \mathrm{~K}$ lower temperature. Furthermore, while the hard films release hydrogen, minor amounts of methane and negligible amounts of higher hydrocarbons, the soft films release significant amounts of larger hydrocar- 
bon molecules up to $\mathrm{C}_{4} \mathrm{H}(\mathrm{D})_{x}$ or $\mathrm{C}_{5} \mathrm{H}(\mathrm{D})_{y}(x \leq 10, y \leq 12)$ [23-25]. Using a-C:H/a-C:D bi-layers it was demonstrated that the released hydrogen and methane molecules are formed in the bulk and diffuse to the surface as molecules [20].

Besides these TPD studies the structural changes of a-C:H under heat treatment have been probed by various techniques. The basic observations can be summarized as follows: The optical gap $E_{04}$ was found to decrease for both hard and soft a$\mathrm{C}: \mathrm{H}$ [26-28]. Fourier transform infrared spectroscopy (FTIR) indicated a transformation of $\mathrm{sp}^{3}$ carbon into $\mathrm{sp}^{2}$ carbon and a loss of hydrogen for both hard and soft films [5, 27, 28], in accord with an aromatization (sometimes also referred to as 'graphitization') observed in Raman spectroscopy by an increase of the D peak intensity and a shift of the $G$ peak position to higher wave numbers [6]. The loss of hydrogen was also confirmed by ion beam analysis $[6,29]$. The electrical resistivity was shown to decrease [30]. Other parameters studied were the film thickness that was found to either decrease [26] or increase $[23,28]$ and the refractive index at fixed wavelength $[5,28]$ that was reported to increase due to annealing in contradiction to our data presented in this paper.

The aim of the present study is to investigate the temperature-induced changes in a wide temperature range of up to $1300 \mathrm{~K}$ with a comprehensive set of analysis techniques using as far as possible initially identical a-C:H and a-C:D films. The optical properties are probed with singlewavelength ellipsometry at $633 \mathrm{~nm}$. Changes of the thickness due to heating are quantified by ellipsometry and/or profilometry. Structural changes of the carbon network are monitored using Raman spectroscopy. The remaining hydrogen content is determined with ion beam analysis and the released hydrogen is monitored using temperature-programmed desorption. The results are discussed and compared to the data reported in the literature.

\section{EXPERIMENTAL}

\section{A. Sample preparation and heating (sets A, B, C and D)}

Several sets of hard a-C:H films were deposited on silicon wafers, heated in vacuo with a base pressure below $10^{-4} \mathrm{~Pa}$ in different devices, and analyzed by various techniques after cooling down.

One set, denoted as set A, was primarily intended to measure temperature-dependent erosion rates (not reported in this paper) of the films when exposed to a flux of atomic hydrogen. The films of this set were deposited onto a silicon wafer on the driven electrode of a capacitively coupled $13.56 \mathrm{MHz}$ rf discharge in a device named KesCaBo, described previously in [31]. Methane with a gas flow of $7.2 \mathrm{sccm}$ was used as working gas and the discharge pressure was $2 \mathrm{~Pa}$. The rf power was set such that a self bias of $-300 \mathrm{~V}$ was achieved. Under these conditions the resulting films were hard a-C:H with a refractive index of $n-\mathrm{i} k=2.15-\mathrm{i} 0.10$ at $633 \mathrm{~nm}$. It is known from earlier $[32,33]$ as well as recent quantitative analysis that films deposited with the quoted deposition parameters have a hydrogen concentration of $\mathrm{H} /(\mathrm{H}+\mathrm{C}) \approx 0.3$ and a carbon den- sity of $\approx 8.5 \times 10^{22} \mathrm{~cm}^{-3}$. Furthermore, it is known that their refractive index is well correlated with the films' properties and can hence serve as a simple characteristic number [32]. The thickness of the films after deposition was approximately $200 \mathrm{~nm}$. The coated wafer was then cut into pieces of approximately $1 \times 1 \mathrm{~cm}^{2}$. For the erosion experiments these small a-C:H coated Si samples were fixed on an electrically heated substrate holder by thin metal strips which shielded parts of the film from exposure to hydrogen, thus preventing erosion in these places. The films were heated to the desired temperature of up to $\approx 1000 \mathrm{~K}$ and held at that temperature for at least $30 \mathrm{~min}$ to be sure that the sample was in thermal equilibrium. The samples were then exposed to atomic hydrogen at that temperature for as long as was required to achieve substantial, but not complete, erosion of the films during $\mathrm{H}$ exposure. Afterwards, the films were cooled down and later scanned across the erosion crater with a single-wavelength $e x$-situ ellipsometer working at $633 \mathrm{~nm}$ to derive the optical properties and the film thickness profile.

Another set of samples, set B, was specifically intended for a study of temperature-induced changes of a-C:H films. In this case, the films were directly deposited to a thickness of approximately $200 \mathrm{~nm}$ in the device PlaQ (for details of the setup see [34]) that also provides a heatable substrate holder and an in situ ellipsometer. Thus, the experimental steps deposition, heat treatment, and the subsequent erosion-necessary to determine the optical properties and thickness after the heat treatment by ellipsometry - could all be performed one after the other without breaking the vacuum and without moving the sample. The films were deposited in a methane ECR plasma at $0.5 \mathrm{~Pa}$ with an additional $\mathrm{rf}$ bias of $-300 \mathrm{~V}$ applied to the substrate. The properties of the films thus obtained are very similar to those of set $\mathrm{A}$ as indicated by their similar refractive index of $n-\mathrm{i} k=2.09-\mathrm{i} 0.07$, measured during the deposition run. The films were then heated to and held at the desired temperature for about one hour. During heating the sample was continuously monitored with ellipsometry. An initial quick shift of the ellipsometric angles was observed (see Fig. 1) that slowed down and almost came to a halt before the end of the heating period at all temperatures. At the end of the heating phase the heater was switched off with no active cooling. For the highest heating temperature the sample cooled to below $600 \mathrm{~K}$ in less than $10 \mathrm{~min}$. After cooling down to $T<330 \mathrm{~K}$ the samples were exposed to an oxygen plasma which erodes the films from the top without modification of their optical properties [35]. Ellipsometry data obtained during this erosion run provide the refractive index and the thickness of the films after heating. The maximum heating temperature of set $\mathrm{B}$ was $\approx 870 \mathrm{~K}$.

A further set of samples, set $\mathrm{C}$, was deposited in the same device and at identical parameters as set $\mathrm{A}$. The thickness of the films was also similar with $\approx 220 \mathrm{~nm}$. The whole coated wafer was again cut into several smaller pieces. Groups of these pieces at a time were then transferred in air to a UHV temperature programmed desorption setup (TESS [25]) where they were heated in vacuo inside a glass tube in a tube furnace. At the start of the heat treatment the preheated furnace was moved from its remote parking position to the heating po- 


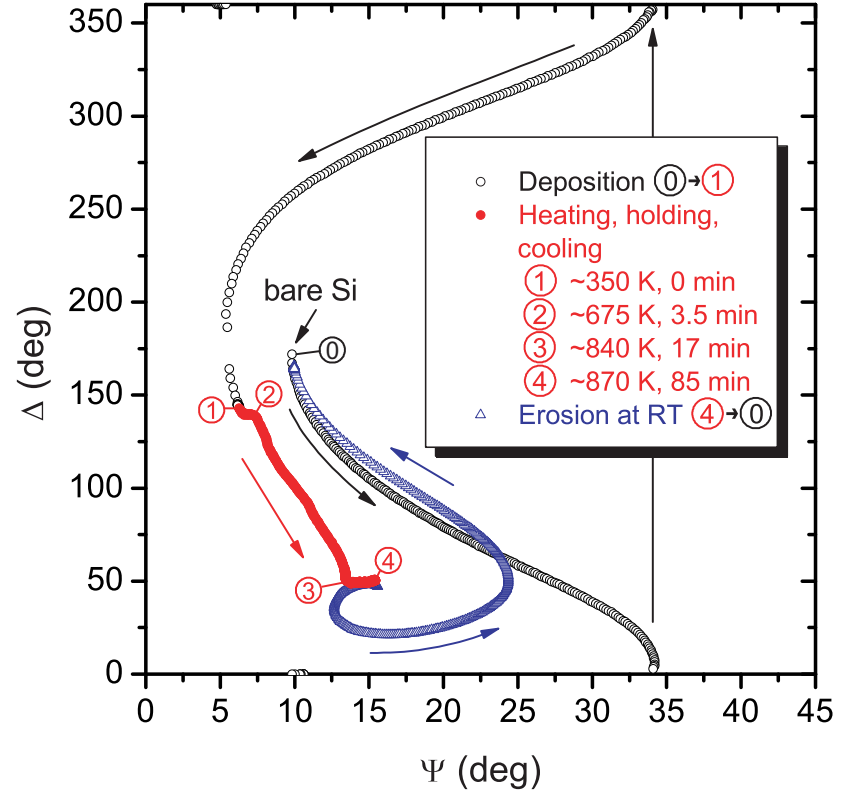

FIG. 1: Ellipsometry raw data, expressed by the ellipsometric angles $\Psi$ and $\Delta$, of a complete deposition-heating-erosion cycle. The film was deposited on the substrate at room temperature (black open circles), then heated to, held at, and cooled down from $870 \mathrm{~K}$ (red solid circles), and finally eroded in an oxygen plasma at room temperature (blue open triangles).

sition, where the samples in the quartz tube are in the middle of the furnace's tube. Thermal equilibrium is reached in about 5 min. The sample was then held at the desired target temperature for about another $30 \mathrm{~min}$ and subsequently cooled down by moving the furnace back to its parking position at a sufficient distance to the quartz tube. Compared to set A this setup had the advantages that higher heating temperatures of up to $1300 \mathrm{~K}$ could be achieved and that the simultaneous heating of several samples was both ensuring identical treatment and time-saving. Samples of set $\mathrm{C}$ were actually heat-treated and analyzed in two campaigns, henceforth called first and second batch.

Finally, set D was produced following the same deposition and heating procedure as set $\mathrm{C}$, except that their initial thickness was $\approx 285 \mathrm{~nm}$ and that deuterated methane was used as source gas. Consequently, the films of set D are deuterated amorphous carbon, a-C:D. The refractive index after heat treatment was determined with ellipsometry and the initial and final thickness was determined by profilometry. In order to produce a step on the samples for profilometry, thin lines were drawn with a permanent marker pen on the silicon wafer's surface. The film does not adhere to these marker lines and the film and marker together can be removed with alcohol after deposition. The heating temperatures of set $\mathrm{D}$ ranged between 650 and $925 \mathrm{~K}$.

In all cases the substrate holders were not actively cooled during deposition and the films and their substrates heated up during the deposition runs due to the heat flux carried by the impinging ions. Measurements of the sample holder temperature during the deposition as well as an estimation of the sample's heat balance indicate that the sample temperature reaches typically $\approx 350 \mathrm{~K}$ and is in any case less than $400 \mathrm{~K}$. The as-deposited samples are therefore shown at $350 \mathrm{~K}$ in Fig. 3 with a $\pm 50 \mathrm{~K}$ error bar.

Special care was taken to ensure correct temperature measurement of the sample surface during heating. The temperature measurement during the heating of set $\mathrm{C}$ may be considered the most accurate. The sample was placed in a quartz tube inside a tube furnace, ensuring a relatively homogeneous temperature distribution. The temperature during heating was measured with a thermocouple placed in the oven but outside the quartz tube, delivering a reading $T_{\text {furnace }}$. Prior to the experiments this thermocouple was compared to another thermocouple glued to a dummy sample and placed in the real sample's stead inside the quartz tube. The temperature reading of this thermocouple is considered the true sample temperature, $T_{\text {sample }}$. Thus, the correlation $T_{\text {sample }}\left(T_{\text {furnace }}\right)$ served to derive the true sample temperature from the reading of the thermocouple in the furnace.

In the case of set B a thermocouple was placed behind the substrate holder and electrically insulated from the holder. As this thermocouple is closer to the heater it has to be assumed that the sample surface will be cooler. In order to correct this temperature reading another thermocouple was glued to the sample surface. It was assumed that this glued thermocouple measures the surface temperature accurately and a calibration relation between the readings of both thermocouples was established. It is worth noting that in the cooling-down phase after switching off the heater the readings of the glued and the rear thermocouples are in good agreement. For set A the temperature was measured by a thermocouple fixed by a screw on the sample holder next to the coated Si sample.

\section{B. Characterization techniques}

The heat treated and some non-heat-treated reference samples were analyzed using various techniques. The complex refractive index of all samples was determined by single wavelength ellipsometry at $633 \mathrm{~nm}$ using a He-Ne laser.

A single ellipsometry measurement only yields two quantities, commonly expressed as the ellipsometric angles $\Psi$ and $\Delta$. However, a measurement of a film with homogeneous optical properties at different thicknesses - two as a bare minimum, but in practice more are required-allows to simultaneously determine thickness $d$ and the real $(n)$ and imaginary $(k)$ parts of the refractive index. Such a measurement is either realized by a spatial scan in a region of varying thickness, such as an erosion crater, or by in situ measurement during deposition or erosion of the film. Fitting the resulting data in the $\Psi-\Delta$ plane by a theoretical curve yields the desired quantities, $n$ and $k$ of the film and a thickness $d$ for each single data point. The method of scanning through an erosion crater was applied to set A to determine the final values of $n, k$, and $d$ after heat treatment. The final values of sets B, C, and D were determined during erosion in an oxygen plasma. The initial values were either determined by ellipsometry during erosion of a non-heated reference sample (sets A, C and D) or during 


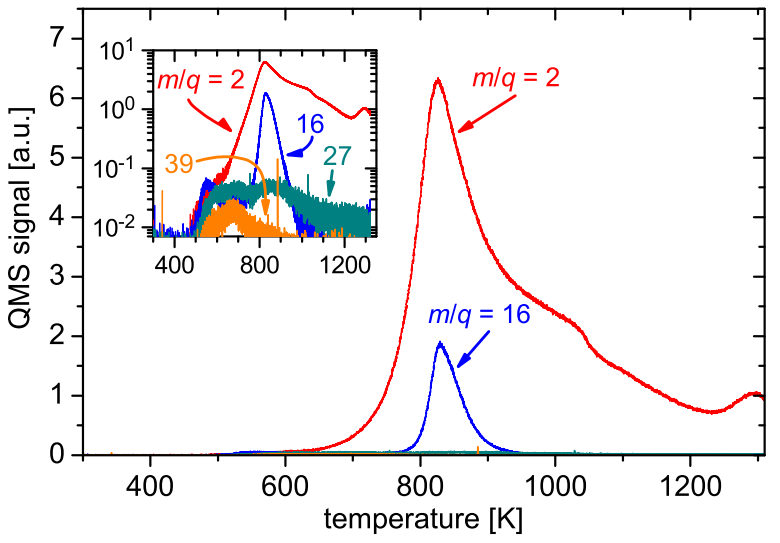

FIG. 2: Raw TPD spectrum, corrected by subtraction of a constant background. The $m / q=2$ signal is produced solely by $\mathrm{H}_{2}, m / q=16$ solely by $\mathrm{CH}_{4}, m / q=27$ can have contributions from $\mathrm{C}_{2} \mathrm{H}_{4}, \mathrm{C}_{2} \mathrm{H}_{6}$, $\mathrm{C}_{3} \mathrm{H}_{8} \ldots$, and $m / q=39$ indicates $\mathrm{C}_{3} \mathrm{H}_{6}$ and higher hydrocarbons.

deposition (set B).

Precise absolute quantification of the areal atom densities is laborious and was conducted only for non-heat-treated a$\mathrm{C}: \mathrm{D}$ and a-C:H reference samples grown under similar conditions. These reference samples were analyzed quantitatively by calibrated TPD and different ion-beam-analysis (IBA) techniques. To derive $\mathrm{C}$ densities, Rutherford backscattering (RBS) with 2 and $4 \mathrm{MeV}{ }^{4} \mathrm{He}$, nuclear reaction analysis (NRA) with $2.4 \mathrm{MeV}{ }^{3} \mathrm{He}$, and proton enhanced scattering (PES) with $1.5 \mathrm{MeV}$ protons was used. $\mathrm{H}$ and $\mathrm{D}$ densities were measured with elastic recoil detection (ERD) with $3 \mathrm{MeV}{ }^{4} \mathrm{He}$. Additionally, D was quantified by NRA with 0.69 and $2.4 \mathrm{MeV}^{3} \mathrm{He}$ and PES with $1.5 \mathrm{MeV}$ protons. A hydrogen content ( $\mathrm{H}$ or $\mathrm{D}$, respectively) of 0.3 was concluded from these measurements.

For the samples of set $\mathrm{C}$ ion beam analysis was employed to quantify only relative changes of the film composition due to the heat treatment. The use of a $3 \mathrm{MeV}^{3} \mathrm{He}$ ion beam under an impact angle of $75^{\circ}$ with respect to the surface normal allowed the simultaneous measurement of ${ }^{1} \mathrm{H}$ in the sample via elastic recoil detection and of ${ }^{12} \mathrm{C}$ via nuclear reaction analysis using the ${ }^{12} \mathrm{C}\left({ }^{3} \mathrm{He}, \mathrm{p}\right){ }^{14} \mathrm{~N}$ reaction.

Apart from determining the residual hydrogen in the film the hydrogen release during heating was also quantified by temperature programmed desorption (TPD) in the quartz tube of the TESS device using samples of set $\mathrm{C}$ and heating them to a maximum temperature of $1320 \mathrm{~K}$. A very low heating rate of $1 \mathrm{~K} / \mathrm{min}$ was applied in order to be as close to the equilibrium $\mathrm{H}$ concentration at every temperature as possible. The TPD spectrum is shown in Fig. 2. Mostly molecular hydrogen and methane are released from the sample. The contributions of higher hydrocarbons, represented here by $m / q=27$ and 39, are negligible. Knowing the initial and final concentrations of hydrogen, $c_{0}$ and $c_{\mathrm{f}}$, the residual hydrogen in the intermediate region at a given time $t$, corresponding to a temperature $T(t)$,

\begin{tabular}{cccccc}
\hline Set & film type & heating & $T$ range & $d_{0}$ & Analysis \\
\hline A & a-C:H & on substrate holder & RT-1000 K $\approx 200 \mathrm{~nm}$ & E(e) \\
B & a-C:H & on substrate holder & RT- $870 \mathrm{~K}$ & $\approx 200 \mathrm{~nm}$ & $\mathrm{E}(\mathrm{i})$ \\
$\mathrm{C}$ & a-C:H & quartz tube/tube furnace & $\mathrm{RT}-1300 \mathrm{~K}$ & $\approx 200 \mathrm{~nm}$ & $\mathrm{E}(\mathrm{e}) / \mathrm{IBA} / \mathrm{R} / \mathrm{TPD}$ \\
$\mathrm{D}$ & a-C:D & quartz tube/tube furnace & $650-925 \mathrm{~K}$ & $\approx 285 \mathrm{~nm}$ & $\mathrm{E}(\mathrm{e}) / \mathrm{P}$ \\
\hline
\end{tabular}

TABLE I: Overview of the sample sets: Sample set, film type (a-C:H or a-C:D), method of heating, range of the heating temperatures, initial thickness $d_{0}$, and applied analyses $(\mathrm{E}(\mathrm{e})=e x$ situ ellipsometry, $\mathrm{E}(\mathrm{i})=$ in situ ellipsometry, $\mathrm{P}=$ profilometry, $\mathrm{IBA}=$ ion beam analysis, $\mathrm{R}=$ Raman spectroscopy, $\mathrm{TPD}=$ temperature programmed desorption).

can be calculated by

$$
c(t)=c_{0}-\left(c_{0}-c_{\mathrm{f}}\right) \cdot \frac{\int_{0}^{t}\left(M_{2}(\tau)+\sigma M_{16}(\tau)\right) \mathrm{d} \tau}{\int_{0}^{t_{\mathrm{f}}}\left(M_{2}(\tau)+\sigma M_{16}(\tau)\right) \mathrm{d} \tau},
$$

where $t_{\mathrm{f}}$ is the time at the end of the TPD measurement, $M_{2}$ and $M_{16}$ are the mass spectrometry signals of $m / q=2\left(\mathrm{H}_{2}\right)$ and $16\left(\mathrm{CH}_{4}\right)$, and

$$
\sigma=\frac{M_{2} \text { signal per } \mathrm{H} \text { atom released as } \mathrm{H}_{2}}{M_{16} \text { signal per } \mathrm{H} \text { atom released as } \mathrm{CH}_{4}}
$$

is the sensitivity ratio. The latter quantity's value $\sigma=1.39$ was determined in calibration measurements with known fluxes of $\mathrm{H}_{2}$ and $\mathrm{CH}_{4}$ admitted into the vacuum chamber through a nozzle. Again, $c_{0}=0.3$ was assumed for the asdeposited sample. The final $\mathrm{H}$ concentration was taken as that derived by IBA for the sample annealed to $1300 \mathrm{~K}$. The little peak in the $\mathrm{H}_{2}$ signal above $1200 \mathrm{~K}$ in Fig. 2 is an artifact due to increasing diffusion of hydrogen through the quartz tube. It appears also without a-C:H sample in the tube. As its contribution to the integral hydrogen signal is small it was not corrected for.

Finally, Raman spectra were recorded with a laser wavelength of $514.5 \mathrm{~nm}, 1 \mathrm{~cm}^{-1}$ resolution and a spot size of $\sim 1 \mu \mathrm{m}^{2}$ in order to characterize structural changes of samples of set $\mathrm{C}$. The probed depth was between a few tens and a few hundreds of $\mathrm{nm}$. Details of the Raman analysis can be found in [36].

Table I gives an overview of the four sets of samples and the analyses applied to them.

\section{RESULTS}

Figure 3 shows all measured parameters of all heat treated and as-deposited samples of sets A to D as a function of annealing temperature. With the exception of the Raman $\mathrm{G}$ peak position, all shown quantities begin to show significant changes from around $700 \mathrm{~K}$ and exhibit their most rapid change with temperature around 800 to $900 \mathrm{~K}$. The good agreement in the overlap region of the first and second batch of set $\mathrm{C}$ shows good reproducibility and the remaining differences can be regarded as an estimation of the experimental uncertainty.

Figure 3 a shows the relative change of the thickness, $d / d_{0}$. The thickness of the films starts increasing above about $600 \mathrm{~K}$. 


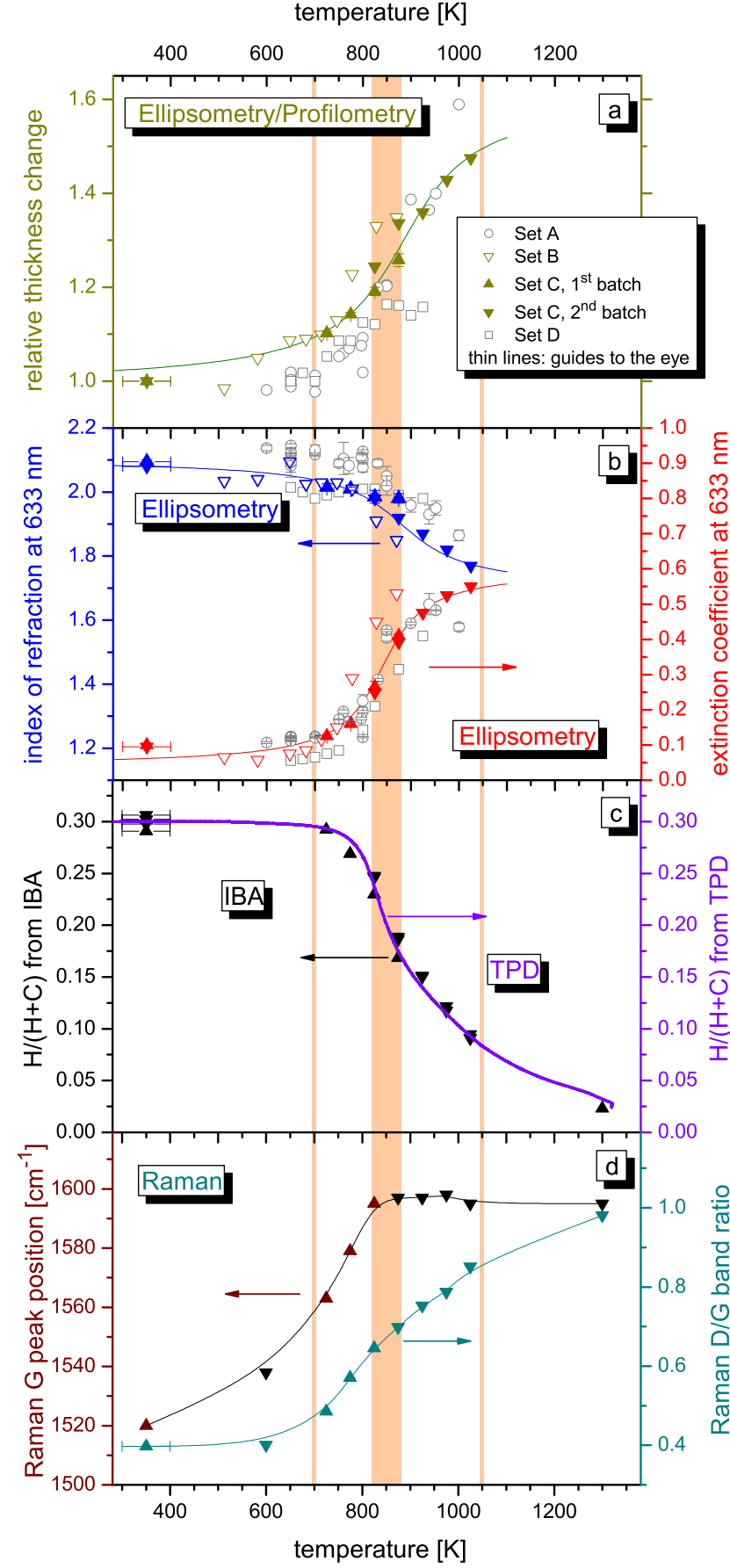

FIG. 3: Properties of the heat-treated samples of sets A to D: a) Relative thickness change (sets A-C: ellipsometry, set D: profilometry), b) real and imaginary part of the refractive index at $633 \mathrm{~nm}, \mathrm{c}$ ) hydrogen concentration as determined by ion beam analysis (symbols) and as determined by TPD (solid line), and d) Raman G peak position and $\mathrm{D} / \mathrm{G}$ band intensity ratio. The thin solid lines in panels $\mathrm{a}$ ), b), and d) are only guides to the eye. The region of the most rapid changes around $850 \mathrm{~K}$ is highlighted in the background. The additional background lines at 700 and $1050 \mathrm{~K}$ are meant to facilitate temperature comparison between the panels.
The maximum change with temperature, $\mathrm{d}\left(d / d_{0}\right) / \mathrm{d} T$, for the data of set $\mathrm{C}$ occurs around $850 \mathrm{~K}$. The maximum observed relative increase of the thickness in sample set $\mathrm{C}$ was by a factor of 1.47 at $1025 \mathrm{~K}$, and for the sample of set A heated to $1000 \mathrm{~K}$ even an increase by a factor of 1.6 was determined. The a-C:D samples of set D show a significantly lower swelling of only up to 1.16 .

Figure $3 \mathrm{~b}$ shows the optical constants of the films. All sample sets show qualitatively the same behaviour; the real part of the refractive index, $n$, starts decreasing with temperature above approximately $700 \mathrm{~K}$ while the imaginary part, $k$, starts increasing around the same temperature. The derivatives $-\mathrm{d} n / \mathrm{d} T$ and $\mathrm{d} k / \mathrm{d} T$ are largest around $850 \mathrm{~K}$, the same temperature where $\mathrm{d}\left(d / d_{0}\right) / \mathrm{d} T$ has its maximum for set $\mathrm{C}$. Above that temperature both $n$ and $k$ appear to be approaching saturation. No values of $n$ and $k$ could be determined of the $1300 \mathrm{~K}$ sample. The raw ellipsometry data could not be fitted with a model assuming a homogeneous bulk of the film, i. e. a single, non-depth-dependent refractive index. A possible explanation could be the formation of silicon carbide around the original $\mathrm{Si} / \mathrm{C}$ interface [37]. For the same reason the swelling of the $1300 \mathrm{~K}$ sample of set $\mathrm{C}$ could also not be quantified.

Figure $3 \mathrm{c}$ shows the $\mathrm{H} /(\mathrm{H}+\mathrm{C})$ ratio of set $\mathrm{C}$ as determined by IBA together with the residual hydrogen content calculated from the slow-ramp TPD experiment on a sample of set $\mathrm{C}$. The hydrogen concentration starts decreasing above $700 \mathrm{~K}$ and the most rapid change occurs again around $850 \mathrm{~K}$. At $1300 \mathrm{~K}$ only about $2.3 \%$ hydrogen is left in the sample. Within the errors no loss of carbon could be detected by IBA (not shown in Fig. 3c). Furthermore, from the mass 16 signal of the TPD experiment we calculate that the absolute loss of carbon is $1 / 37$ of the loss of hydrogen, or approximately $1 \%$ of the initial carbon. The agreement between $\mathrm{H} /(\mathrm{H}+\mathrm{C})$ from IBA and TPD is excellent. Due to the very slow TPD temperature ramp no temperature shift between IBA and TPD data is observed.

Figure $3 \mathrm{~d}$ shows the peak height ratio $I_{\mathrm{D}} / I_{\mathrm{G}}$ of the Raman $\mathrm{D}$ and $\mathrm{G}$ peaks and the $\mathrm{G}$ peak position. The corresponding raw spectra can be found in [36]. We find that both $I_{\mathrm{D}} / I_{\mathrm{G}}$ and the $\mathrm{G}$ peak position increase with annealing temperature. These trends are a clear indication of an increase of aromatic domain size $[38,39]$. The detailed temperature evolution of the Raman parameters reveals that the $G$ peak position already shifts in a temperature range in which none of the other measured quantities changes and it saturates already at around $800 \mathrm{~K}$. The peak height ratio appears to be generally well correlated with the $\mathrm{H} /(\mathrm{H}+\mathrm{C})$ ratio, yet setting in at slightly lower temperatures than hydrogen loss. These differences indicate that structural reorganization and hydrogen loss are at least partially independent processes with different activation energies.

\section{DISCUSSION}

A remarkable result of our study is the huge thickness increase exceeding a factor of 1.4 at annealing temperatures around $1000 \mathrm{~K}$. It might be very tempting to explain this swelling in terms of stress release: Films deposited with energetic ion bombardment, as is the case for our films, are known 


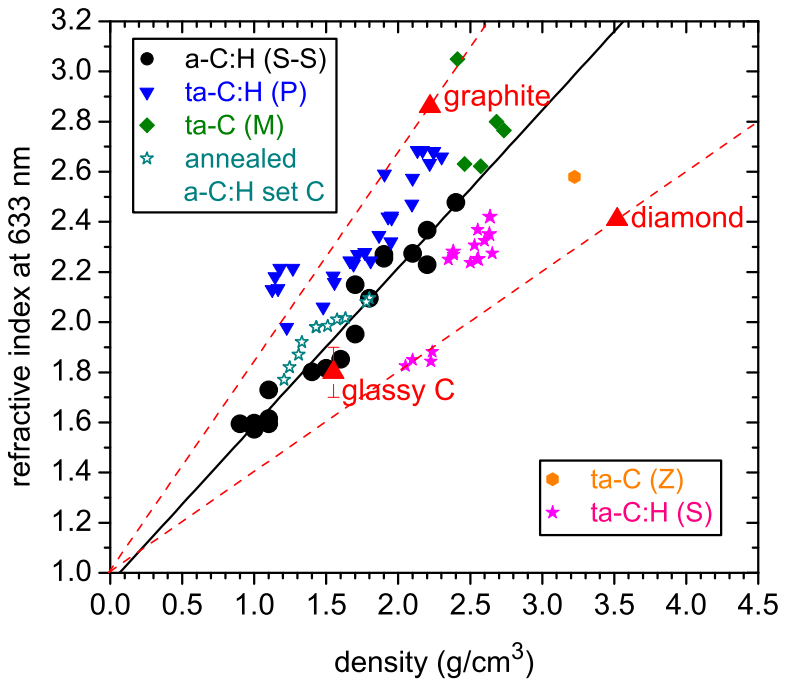

FIG. 4: Refractive index at $633 \mathrm{~nm}$ versus mass density for a variety of carbon materials taken from the literature. The materials are diamond [40], graphite [41], glassy carbon [42], plasma-deposited a-C:H (a-C:H (S-S) [32]), plasma deposited ta-C:H (ta-C:H (P) [43] and ta-C:H (S) [44]), and ta-C produced by pulsed laser deposition (ta-C (M) [45]) and by pulsed filtered vacuum arc deposition (ta-C (Z) [45]). The black solid line is a linear fit to the a-C:H data, the red dashed lines connect the origin $(\rho=0, n=1)$ with graphite and diamond. The as-deposited and annealed samples of set $\mathrm{C}$ are also shown.

to have compressive stress $[46,47]$. The presence of compressive stress in our films is also confirmed by the observation of convex bending of the silicon wafer substrate. Annealing is known to lead to a reduction of this stress [5, 7, 8, 48, 49]. One might hence argue that at sufficiently high temperatures at which structural reorganization can occur this stress drives an expansion of the film. Without delamination from the substrate, this expansion could only happen in the direction normal to the surface. As our hard a-C:H films lose only minor amounts of carbon during annealing, as was quantitatively confirmed by IBA and TPD, this expansion shows up as a net increase in thickness. However, if we compare the volume change to the ratio of stress and bulk modulus it becomes evident, that stress release cannot account for a swelling of the films anywhere near the one observed. For slightly thicker films deposited in the same device as set B at a bias voltage of $-280 \mathrm{~V}$ under otherwise very similar deposition conditions a stress value of $1.2 \mathrm{GPa}$ was determined from substrate bending (unpublished). A very similar value of $1.34 \mathrm{GPa}$ was reported by Grill et al. [5] for hard a-C:H deposited from $\mathrm{C}_{2} \mathrm{H}_{2}$. For the bulk modulus of hard a-C:H deposited from $\mathrm{C}_{2} \mathrm{H}_{2}$ at $-300 \mathrm{~V}$ substrate bias Jiang et al. [50] determined a value of $\sim 135 \mathrm{GPa}$. Hence, a volume increase of only about $1 \%$ should be enough to release the stress. Film swelling and stress release therefore appear to be two not necessarily interrelated consequences of thermally induced structural changes.

Light absorption is almost entirely due to the $\mathrm{sp}^{2}$ carbon $[4,51]$. Hence, $k$ increases as the $\mathrm{sp}^{2}$ fraction and cluster size increase. An explanation of the variation of the real part of the refractive index, $n$, is less straightforward. Figure 4 shows $n$ versus mass density for a variety of carbon materials as reported in the literature. There is a huge variation of $n$ at constant $\rho$. The boundaries of the populated region in the $\rho-n$ plane appear to be given by the dashed lines that connect the data for graphite and diamond with the point $(\rho=0, n=1)$. For materials of a similar structure, e.g. a-C:H, $(n-1)$ appears to be directly proportional to $\rho$. The linear least squares fit to the a-C:H data of Ref. $[32], n=0.959+0.628 \cdot \rho\left[\mathrm{g} / \mathrm{cm}^{3}\right]$, shown as solid black line in Fig. 4, indeed approximates the data well and passes very close to the refractive index of vacuum at zero density. Therefore we speculate that the decrease of $n$ with annealing temperature is primarily a consequence of the density decrease as the films expand. This is supported by the data corresponding to those samples of set $\mathrm{C}$, for which ellipsometry could be evaluated. They are also shown in Fig. 4. For both batches of these samples the original density $\rho_{0}$ was calculated from the initial refractive index $n_{0}$ using the fit to the a-C:H data. The density of an annealed sample, $\rho$, was then calculated from the original density $\rho_{0}$ and the thickness change $d / d_{0}$ by $\rho=\rho_{0}\left(d_{0} / d\right)$. The evolution of $(\rho, n)$ of set $\mathrm{C}$ closely follows the black solid line.

While there is very little scatter in all the data of set $\mathrm{C}$ in Fig. 3, there are significant differences between the different sets of samples in Fig. 3a and b. One possible reason is the accuracy of the temperature measurement. As explained in the introduction, the temperature calibration of set $\mathrm{C}$ is considered the most reliable while those of sets $\mathrm{A}$ and $\mathrm{B}$ might suffer from the largest systematic errors. The deviations between sets $\mathrm{B}$ and $\mathrm{C}$ might be ascribed to an increasing difference between thermocouple and sample surface temperature with increasing temperature. The samples of set A have a slightly higher initial refractive index than the samples of sets $\mathrm{B}$ and $\mathrm{C}$ ( $n(\mathrm{~A})=2.14$ versus $n(\mathrm{C})=2.09$ ). This is probably also the reason why their refractive index stays higher for all annealing temperatures. However, the relative variation of $n$ and $k$ for set $\mathrm{A}$ is in very good agreement with set C. For the samples of set $\mathrm{D}$ it has to be considered that they are a-C:D, not $\mathrm{a}-\mathrm{C}: \mathrm{H}$ like all the other sample sets. Although ion beam analysis reveals similar $\mathrm{H} /(\mathrm{H}+\mathrm{C})$ and $\mathrm{D} /(\mathrm{D}+\mathrm{C})$ ratios of films deposited from $\mathrm{CH}_{4}$ and $\mathrm{CD}_{4}$ with the same self-bias, absolute densities of carbon and hydrogen in the films turn out to be lower for the deuterated films [52]. This observation was tested independently by growing $300 \mathrm{~nm}$ thick a-C:H and a$\mathrm{C}: \mathrm{D}$ films under identical conditions $(-300 \mathrm{~V}$ self-bias, $2.0 \mathrm{~Pa}$ neutral pressure, identical pumping speed) and measuring the mass increase due to the deposition ex situ by a microbalance. The thickness was determined locally and in situ with interferometry as well as laterally resolved with an ex situ tactile profilometer. While the a-C:H film had a density of $1.8 \mathrm{~g} / \mathrm{cm}^{3}$ the a-C:D film had only $1.7 \mathrm{~g} / \mathrm{cm}^{3}$. These obviously different film properties may be the cause of the lower swelling. The thickness increase reported by Maruyama et al. [23] for hard a-C:D of less than $15 \%$ up to $900 \mathrm{~K}$ annealing temperature agrees well with our results of set $\mathrm{D}$.

Comparing our data to results reported in the literature we 
find the loss of hydrogen and the conversion of $\mathrm{sp}^{3}$ into $\mathrm{sp}^{2}$ carbon univocally confirmed (see the introduction). For films with an initial $\mathrm{H}$ content very similar to that of our films, $\mathrm{Wu}$ et al. [6] show a temperature-dependent dehydrogenation during rapid thermal annealing that agrees excellently with our results. The evolution of their Raman spectra also agrees very well with ours up to $1173 \mathrm{~K}\left(900^{\circ} \mathrm{C}\right)$. The only qualitative difference is that their their $I_{\mathrm{D}} / I_{\mathrm{G}}$ ratio decreases again between 1173 and $1273 \mathrm{~K}\left(900\right.$ and $\left.1000^{\circ} \mathrm{C}\right)$ and the $\mathrm{G}$ peak redshifts slightly from 1600 to $1585 \mathrm{~cm}^{-1}$, indicating an increase of the graphitic crystallite size [7], while our films show no such development between 1000 and $1300 \mathrm{~K}$.

Regarding the thickness evolution we find contradictory results in the literature. While Ritikos et al. [28] find an increase of the thickness during annealing like we do, Zhang et al. [53] find a decrease. The reason for this apparent contradiction could be the different nature of the a-C:H films in these studies. While our films are hard ("diamondlike") and those of Ritikos et al. seem to belong to this class of films too, the films of Zhang et al. are soft ("polymerlike") [54]. Soft films emit significant amounts of hydrocarbon molecules during annealing leading to a marked decrease of carbon and hence a decrease of the thickness. On the contrary, hard films emit mostly molecular hydrogen and only minor amounts of methane. In their case the thickness increase due to structural reorganization outweighs the negligible loss of carbon.

A still unresolved difference is the behaviour of the refractive index in the visible/near infrared range. While we find a decrease of $n$ at $633 \mathrm{~nm}$ with temperature, Grill et al. [5] report an increase at the same wavelength and Ritikos et al. [28] report an increase of $n$ at much longer wavelength, probably at $2500 \mathrm{~nm}$. The films of Grill et al. were deposited from $\mathrm{C}_{2} \mathrm{H}_{2}$ at $-80 \mathrm{~V}$ bias and they have $n \sim 1.9$. These films should be similar to, yet slightly more polymerlike than our films [32]. Unfortunately Grill et al. give no details of the procedure by which they obtained $n$ after annealing by ellipsometry.

\section{SUMMARY AND CONCLUSIONS}

Hard hydrogenated amorphous carbon films (a-C:H and a$\mathrm{C}: \mathrm{D})$ were annealed at different temperatures and analyzed by various techniques after cooling down. The first observable change with temperature is the shift of the Raman $G$ peak position to higher wave numbers. This shift indicates a structural modification that in this temperature range is not accompanied by loss of hydrogen. Above 600 to $700 \mathrm{~K}$ the other observed quantities do also change. Above $600 \mathrm{~K}$ an increase of the Raman $I_{\mathrm{D}} / I_{\mathrm{G}}$ ratio indicates aromatization of the films. Starting from about $700 \mathrm{~K}$ the ellipsometrically determined refractive index at $633 \mathrm{~nm}$ decreases while the extinction coefficient increases simultaneously. Ellipsometry also revealed that these changes are accompanied by an increase of the film thickness by up to $\sim 50 \%$ at an annealing temperature of $1000 \mathrm{~K}$. The loss of hydrogen from the samples was quantified both by measuring the residual hydrogen with ion beam analysis and by monitoring the desorbing hydrogen by slow-ramp $(1 \mathrm{~K} / \mathrm{min})$ temperature programmed desorption. The temperature dependence derived with both techniques is in excellent agreement. The hydrogen loss occurs in the same temperature range as the change of the other parameters and after annealing at $1300 \mathrm{~K} \mathrm{H} /(\mathrm{H}+\mathrm{C})$ is only about $2.3 \%$. The most rapid change of all measured parameters except the $\mathrm{G}$ peak position with temperature occurs around $850 \mathrm{~K}$.

The huge thickness increase is probably a consequence of the structural reorganization evidenced by Raman spectroscopy. Although annealing is known to reduce residual compressive stress present in this type of films, the magnitude of volume increase rules out stress release as the driving force. The observed decrease of the refractive index seems to be a direct consequence of the swelling as the refractive index was found to be directly proportional to mass density.

\section{Acknowledgement}

The authors would like to acknowledge the contribution of Nele Gehrken, who performed a substantial number of the measurements during an internship at IPP.
[1] C. A. Charitidis, Nanomechanical and nanotribological properties of carbon-based thin films: A review, Int. J. Refract. Met. Hard Mater. 28 (2010) 51.

[2] J. F. Martinatti, L. V. Santos, N. C. Cruz, E. C. Rangel, Hydrogenated amorphous carbon as protective coating for a forming tool, Eur. Phys. J. Appl. Phys. 56 (2011) 24014.

[3] M.-L. Theye, V. Paret, Hydrogenated amorphous carbon: A complex and versatile form of disordered carbon, Cond. Matter News 7 (1998) 4.

[4] J. Robertson, Diamond-like amorphous carbon, Mat. Sci. Eng. Reports 37 (2002) 129.

[5] A. Grill, V. Patel, B. S. Meyerson, Optical and tribological properties of heat-treated diamond-like carbon, J. Mater. Res.
5 (1990) 2531.

[6] R. L. C. Wu, K. Miyoshi, R. Vuppuladhadium, H. E. Jackson, Physical and tribological properties of rapid thermal annealed diamond-like carbon films, Surf. Coat. Technol. 54\&55 (1992) 576.

[7] A. C. Ferrari, B. Kleinsorge, N. A. Morrison, A. Hart, V. Stolojan, J. Robertson, Stress reduction and bond stability during thermal annealing of tetrahedral amorphous carbon, J. Appl. Phys. 85 (1999) 7191.

[8] H. W. Choi, D. M. Gage, R. H. Dauskardt, K.-R. Lee, K. H. Oh, Effects of thermal annealing and Si incorporation on bonding structure and fracture properties of diamind-like carbon films, Diamond Relat. Mater. 18 (2009) 615. 
[9] J.-F. Yu, T.-S. Chen, H.-C. Lin, S.-T. Shiue, The effect of rapid thermal annealing on characteristics of carbon coatings on optical fibers, Phys. Status Solidi A 207 (2010) 379.

[10] A. Grigonis, Ž. Rutkunienè, H. Manikowski, M. Šilinskas, Laser-induced transformation of a-C:H thin films, Vacuum 83 (2009) S152.

[11] E. Cappelli, C. Scilletta, S. Orlando, V. Valentini, M. Servidori, Laser annealing of amorphous carbon films, Appl. Surf. Sci. 255 (2009) 5620.

[12] G. Federici, C. H. Skinner, J. N. Brooks, J. P. Coad, C. Grisolia, A. A. Haasz, A. Hassanein, V. Philipps, C. S. Pitcher, J. Roth, W. R. Wampler, D. G. Whyte, Plasma-material interactions in current tokamaks and their implications for next step fusion reactors, Nucl. Fusion 41 (2001) 1967.

[13] P. Andrew, D. Brennan, J. P. Coad, J. Ehrenberg, M. Gadeberg, A. Gibson, M. Groth, J. How, O. N. Jarvis, H. Jensen, R. Lässer, F. Marcus, R. Monk, P. Morgan, J. Orchard, A. Peacock, R. Pearce, M. Pick, A. Rossi, B. Schunke, M. Stamp, M. von Hellermann, D. L. Hillis, J. Hogan, Tritium recycling and retention in JET, J. Nucl. Mater. 266-269 (1999) 153.

[14] W. Jacob, Redeposition of hydrocarbon layers in fusion devices, J. Nucl. Mater. 337-339 (2005) 839.

[15] T. Dittmar, P. Roubin, E. Tsitrone, E. Gauthier, A. Hakola, J. Likonen, F. Linez, C. Martin, M. Mayer, C. Pardanaud, J. Y. Pascal, B. Pasquet, B. Pégourié, J. Roth, I. Roure, R. Ruffe, Deuterium inventory in Tore Supra: status of post-mortem analyses, Phys. Scr. T138 (2009) 014027.

[16] C. Pardanaud, G. Giacometti, C. Martin, R. Ruffe, T. Angot, E. Aréou, B. Pégourié, E. Tsitrone, T. Dittmar, C. Hopf, W. Jacob, T. Schwarz-Selinger, P. Roubin, Raman study of CFC tiles extracted from the toroidal pump limiter of Tore Supra, J. Nucl. Mater. 415 (2011) S254.

[17] C. Hopf, W. Jacob, V. Rohde, Oxygen glow discharge cleaning in nuclear fusion devices, J. Nucl. Mater. 374 (2008) 413.

[18] J. Roth, E. Tsitrone, A. Loarte, T. Loarer, G. Counsell, R. Neu, V. Philipps, S. Brezinsek, M. Lehnen, P. Coad, C. Grisolia, K. Schmid, K. Krieger, A. Kallenbach, B. Lipschultz, R. Doerner, R. Causey, V. Alimov, W. Shu, O. Ogorodnikova, A. Kirschner, G. Federici, A. Kukushkin, EFDA PWI Task Force, ITER PWI Team, Fusion for Energy, ITPA SOL/DIV, Recent analysis of key plasma wall interactions issues for ITER, J. Nucl. Mater. 390-391 (2009) 1.

[19] A. von Keudell, W. Möller, R. Hytry, Deposition of dense hydrocarbon films from a nonbiased microwave plasma, Appl. Phys. Lett. 62 (1993) 937.

[20] C. Wild, P. Koidl, Thermal gas effusion from hydrogenated amorphous carbon films, Appl. Phys. Lett. 51 (1987) 1506.

[21] X. Jiang, W. Beyer, K. Reichelt, Gas evolution from hydrogenated amorphous carbon films, J. Appl. Phys. 68 (1990) 1378.

[22] J. Ristein, R. T. Stief, L. Ley, W. Beyer, A comparative analysis of a-C:H by infrared spectroscopy and mass selected thermal effusion, J. Appl. Phys. 84 (1998) 3836.

[23] K. Maruyama, W. Jacob, J. Roth, Erosion behavior of soft, amorphous deuterated carbon films by heat treatment in air and under vacuum, J. Nucl. Mater. 264 (1999) 56.

[24] W. Jacob, C. Hopf, A. von Keudell, T. Schwarz-Selinger, Hydrogen recycling at plasma facing materials, Kluwer Academic Publishers, Dordrecht, 2000, Ch. Surface loss probabilities of hydrocarbon radicals on amorphous hydrogenated carbon film surfaces: consequences for the formation of re-deposited layers in fusion experiments, pp. 331-337.

[25] E. Salançon, T. Dürbeck, T. Schwarz-Selinger, F. Genoese, W. Jacob, Redeposition of amorphous hydrogenated carbon films during thermal decomposition, J. Nucl. Mater. 376 (2008) 160.

[26] Q. Zhang, S. F. Yoon, Rusli, H. Yang, J. Ahn, Influence of oxygen on the thermal stability of amorphous hydrogenated carbon films, J. Appl. Phys. 83 (1998) 1349.

[27] Z. L. Akkerman, H. Efstathiadis, F. W. Smith, Thermal stability of diamondlike carbon films, J. Appl. Phys. 80 (1996) 3068.

[28] R. Ritikos, C. C. Siong, S. M. A. Gani, M. R. Muhamad, S. A. Rahman, Effect of annealing on the optical and chemical bonding properties of hydrogenated amorphous carbon and hydrogenated amorphous carbon nitride thin films, Jap. J. Appl. Phys. 48 (2009) 101301.

[29] A. Kayani, A. Moore, M. I. Nandasiri, S. AlFaify, E. Garratt, D. Ingram, M. Maqbool, Effect of bias and hydrogenation on the elemental concentration and the thermal stability of amorphous thin carbon films, deposited on Si substrate, Diamond Relat. Mater. 18 (2009) 1333.

[30] T. M. Wang, W. J. Wang, B. L. Chen, S. H. Zhang, Electrical and optical properties and structural changes of diamondlike carbon films during thermal annealing, Phys. Rev. B 50 (1994) 5587.

[31] A. Annen, R. Beckmann, W. Jacob, Deposition and characterization of dense and stable amorphous hydrogenated boron films at low substrate temperatures, J. Non-Cryst. Solids 209 (1997) 240.

[32] T. Schwarz-Selinger, A. von Keudell, W. Jacob, Plasma chemical vapor deposition of hydrocarbon films: The influence of hydrocarbon source gas on the film properties, J. Appl. Phys. 86 (1999) 3988.

[33] A. Annen, Amorphe hydrogenisierte Bor-Kohlenstoff-Filme: Herstellung, Charakterisierung und Untersuchung des Erosionsverhaltens, Ph.D. thesis, Universität Bayreuth (1997).

[34] B. Landkammer, A. von Keudell, W. Jacob, Erosion of thin hydrogenated carbon films in oxygen, oxygen/hydrogen and water plasmas, J. Nucl. Mater. 264 (1999) 48

[35] A. von Keudell, W. Jacob, W. Fukarek, Role of hydrogen ions in plasma enhanced chemical vapor deposition of hydrocarbon films, investigated by in situ ellipsometry, Appl. Phys. Lett. 66 (1995) 1322.

[36] C. Pardanaud, C. Martin, P. Roubin, G. Giacometti, C. Hopf, T. Schwarz-Selinger, W. Jacob, Raman spectroscopy investigation of the $\mathrm{H}$ content of heated hard amorphous carbon layers, Diamond. Relat. Mater. 34 (2013) 100.

[37] C. Linsmeier, J. Luthin, P. Goldstraß, Mixed material formation and erosion, J. Nucl. Mater. 290-293 (2001) 25.

[38] A. C. Ferrari, J. Robertson, Interpretation of Raman spectra of disordered and amorphous carbon, Phys. Rev. B 61 (2000) 14095.

[39] C. Casiraghi, A. C. Ferrari, J. Robertson, Raman spectroscopy of hydrogenated amorphous carbons, Phys. Rev. B 72 (2005) 085401.

[40] W. M. Haynes (Ed.), Handbook of chemistry and physics, 93rd Edition, CRC Press/Taylor and Francis, Boca Raton, Florida, 2013.

[41] A. Borghesi, G. Guizzetti, Handbook of optical constants of solids II, Academic Press, 1991, Ch. Graphite (C), p. 449.

[42] D. McCulloch, A. Hoffman, S. Prawer, Ion-beam induced compaction in glassy carbon, J. Appl. Phys. 74 (1993) 135.

[43] F. Piazza, Hard-hydrogenated tetrahedral amorphous carbon films by distributed electron cyclotron resonance plasma, Int. J. Refract. Met. Hard Mater. 24 (2006) 39.

[44] S. Sattel, J. Robertson, H. Ehrhardt, Effects of deposition temperature on the properties of hydrogenated tetrahedral amorphous carbon, J. Appl. Phys. 82 (1997) 4566 
[45] Y. Miyajima, S. J. Henley, G. Adamopoulos, V. Stolojan, E. Garcia-Caurel, B. Drévillon, J. M. Shannon, S. R. P. Silva, Pulsed laser deposited tetrahedral amorphous carbon with high $\mathrm{sp}^{3}$ fractions and low optical bandgaps, J. Appl. Phys. 105 (2009) 073521

[46] C. A. Davis, A simple model for the formation of compressive stress in thin films by ion bombardment, Thin Solid Films 226 (1993) 30.

[47] J. Robertson, Deposition mechanisms for promoting $\mathrm{sp}^{3}$ bonding in diamond-like carbon, Diamond Relat. Mater. 2 (1993) 984

[48] J. P. Sullivan, T. A. Friedmann, A. G. Baca, Stress relaxation and thermal evolution of film properties in amorphous carbon, J. Electron. Mater. 26 (1997) 1021

[49] T. M. Alam, T. A. Friedmann, P. A. Schultz, D. Sebastiani, Low temperature annealing in tetrahedral amorphous carbon thin films observed by ${ }^{13} \mathrm{C}$ NMR spectroscopy, Phys. Rev. B 67 (2003) 245309.
[50] X. Jiang, K. Reichelt, B. Stritzker, Mechanical properties of a$\mathrm{C}: \mathrm{H}$ films prepared by plasma decomposition of $\mathrm{C}_{2} \mathrm{H}_{2}$, J. Appl. Phys. 68 (1990) 1018.

[51] J. Robertson, Structural models for a-C and a-C:H, Diamond Relat. Mater. 4 (1995) 297.

[52] R. Hartwich, Herstellung und Charakterisierung von a-C:H und a-C:D Schichten mit variablem Wasserstoffgehalt, Master's thesis, Munich University of Applied Sciences (2008).

[53] Q. Zhang, S. F. Yoon, Rusli, J. Ahn, H. Yang, D. Bahr, Deposition of hydrogenated diamond-like carbon films under the impact of energetic hydrocarbon ions, J. Appl. Phys. 84 (1998) 5538.

[54] S. F. Yoon, H. Yang, A. Rusli, J. Ahn, Q. Zhang, The effects of self-generated DC bias on the characteristics of diamondlike carbon films prepared using ECR-CVD, Diamond Relat. Mater. 7 (1998) 70. 